\title{
Porous and chelated nanostructured multifunctional materials: recoverable and reusable sorbents for extraction of metal ions and catalysts for diverse organic reactions
}

\author{
Parul Pant $^{1} \cdot$ Ritu Bansal $^{2} \cdot$ Shikha Gulati $^{2} \cdot$ Sanjay Kumar $^{2} \cdot$ Rishi Kodwani $^{2}$
}

Received: 12 January 2016/Accepted: 22 March 2016/Published online: 5 April 2016

(c) The Author(s) 2016. This article is published with open access at Springerlink.com

\begin{abstract}
This review article gives an insight into recent developments in chelating agents modified nanostructures in metal extraction and catalysis. The ability of functionalization by anchoring specific functional groups on the surface of nanostructures makes it possible to synthesize different types of desired chelated nanostructures for their use as catalysts and metal ion scavengers. Keeping these aspects in outlook this review emphasizes mainly on the synthesis of chelating agent functionalized nanostructures and their applications in the field of metal ion extraction and catalysis. The review article provides comprehensive information about the work that has been done in the past 5 years in the field of metal ion extraction and catalysis using chelating agent modified nanoparticles.
\end{abstract}

Keywords Porous - Chelated - Nanoparticles - Catalysts . Sorbents $\cdot$ Metal ions $\cdot$ Reusable

\section{Introduction}

Environmental pollution and hence affected human health due to release of metal ions in the environment, particularly as industrial waste, poses a serious problem. The removal and recovery of these metal ions is, therefore, a significant concern [1]. The key to extract these metal ions in an economically viable manner lies in the use of highly efficient, cost-effective and environmentally acceptable techniques. A broad range of physiochemical separation processes such as precipitation,

Parul Pant

shikha2gulati@gmail.com

1 Hansraj College, University of Delhi, Delhi, India

2 Sri Venkateswara College, University of Delhi, Delhi, India sorption, membrane processes, electrolytic recovery, solidphase extraction (SPE) and liquid-liquid extraction are available for this purpose [2-5]. Among these techniques, SPE is fast, generates less waste, regenerates the solid phase and does not require toxic solvents. Therefore, SPE has emerged as a powerful tool for separation/enrichment of metal ions using modified sorbents [6]. Further, chelation plays an important role in enhancing their adsorption capacity and easy separation. Chelated sorbents are more efficient and can be recovered and reused for many cycles [7-9].

In recent years, nanotechnology has emerged as one of the most key technologies in the field of metal extraction, catalysis, pharmacy, biotechnology, electronics, etc. [1012]. The fabrication of nanostructured chelated sorbents, particularly for metal ion extraction, is emerging as an important field of analytical chemistry due to their unique properties [13]. Nanostructured sorbents show high surface reactivity with their large surface areas so that their surfaces can be easily modified by various chelating agents [14]. Chelating agent modified nanoparticles, being highly selective can easily bind to metal ions with strong chemical activities, thus providing high sorption capacity, high enrichment factors for separation and recovery of various metal ions. For this purpose, accurate selection of appropriate support and chelating agent is required for full recovery of metal ions with high enrichment factor [15].

In addition to the application of nanostructured materials for extraction of metal ions, the use of these materials to catalyse diverse organic reactions has received much attention in recent times [16-24]. It is well known that activity of catalysts depend on size, dimensions and morphologies and, therefore, the porous and nanostructured materials are expected to exhibit enhanced catalytic efficiency and reusability [25-27]. These porous and chelated nanostructured multifunctional materials, along with their 
metal extraction and catalytic properties, have also shown biological activities such as antibody purification from human plasma, removing oxidative stress, etc. [28-32]. But, in the present review, we have focused on the synthesis and application of porous and chelated nanostructured multifunctional materials for extraction of metal ions and as catalysts for diverse organic reactions.

\section{Porous and chelated nanostructured materials for extraction of metal ions}

The extraction of metal ion plays a significant role in soil, air and water remediation. Nanoparticles provide high surface area and are, therefore, suitable for this purpose. The extraction of metal ions, as explained earlier, can be done easily and efficiently by SPE.

SPE technique requires a support material to prepare an efficient sorbent. Based on the chemical nature, these can be divided as inorganic sorbents including modified metal/ metal oxide nanoparticles, organic sorbents (generally carbon nanotubes) and organic-inorganic based sorbents (Table 1) [33-35]. In general, nanostructured sorbent systems are fabricated by functionalization of ligands over sorbent coated nanoparticles followed by metal immobilization (Fig. 1; Table 2).

\section{Inorganic-based sorbents}

The use of surfactant-coated mineral oxides (generally alumina and silica) as sorbent materials has received much attention for extraction of various metal ions. These sorbent materials provide high surface areas. The modification of sorbent helps in their selectivity and increased activity. The most commonly used methods of modification are physisorption and chemisorption. However, chemical methods provide high stability and reusability.

\section{Alumina nanoparticles}

Afkhami et al. modified alumina nanoparticles with 2,4dinitrophenylhydrazine (DNPH) by prior treatment with sodium dodecyl sulphate (SDS) for increasing its adsorption capacity. They found that SDS-coated alumina formed hemi-micelles which trapped DNPH molecules homogeneously, thus changing colour of alumina from white to orange. The immobilization of DNPH on SDS-coated alumina nanoparticles favoured uptake of metal ions by complex formation, thus extracting metal ions like $\mathrm{Pb}(\mathrm{II})$, $\mathrm{Cr}(\mathrm{III}), \mathrm{Cd}(\mathrm{II})$ efficiently [2]. Ezoddina et al. coated nanosized alumina with sodium dodecyl sulphate-1-(2-pyridylazo)-2-naphthol (SDS-PAN) by formation of hemi-micelles. They observed that at lower $\mathrm{pH}$, positively charged nano- $\gamma$-alumina surfaces sorbed negatively charged SDS efficiently. These modified alumina nanoparticles were used for preconcentration of $\mathrm{Cd}$ and $\mathrm{Pb}$ samples [15].

Baezzat et al. modified SDS-coated alumina nanoparticles with 3-mercapto-D-valine. They found that coating alumina nanoparticles with SDS provided greater efficiency for metal ion recovery. The presence of free lone pairs on nitrogens of the ligand coordinated with metal ions, thus causing their extraction. This method provided higher recoveries of zinc, iron and copper ions [36].

\section{Magnetic nanoparticles}

The use of magnetic nanoparticles has provided better kinetics for adsorption of metal ions. Zhai et al. modified

Table 1 Various chelated nanostructured inorganic sorbent-support systems for extraction of metal ions

\begin{tabular}{|c|c|c|c|c|}
\hline $\begin{array}{l}\text { S. } \\
\text { no. }\end{array}$ & Support material & Ligand & $\begin{array}{l}\text { Selective for following } \\
\text { metal ion }\end{array}$ & References \\
\hline 1. & Alumina nanoparticles & 2,4-Dinitrophenylhydrazine & $\begin{array}{l}\mathrm{Pb}(\mathrm{II}), \mathrm{Cd}(\mathrm{II}), \mathrm{Cr}(\mathrm{III}) \\
\quad \mathrm{Co}(\mathrm{II}), \mathrm{Ni}(\mathrm{II}) \text { and } \mathrm{Mn}(\mathrm{II})\end{array}$ & [2] \\
\hline 2. & Alumina nanoparticles & Sodium dodecyl sulphate-1-(2-pyridylazo)-2-naphthol & $\mathrm{Cd}(\mathrm{II})$ and $\mathrm{Pb}(\mathrm{II})$ & [15] \\
\hline 3. & Alumina nanoparticles & Sodium dodecyl sulphate, 3-mercapto-D-valine & $\mathrm{Zn}(\mathrm{II}), \mathrm{Fe}(\mathrm{II})$ and $\mathrm{Cu}(\mathrm{II})$ & [36] \\
\hline 4. & $\begin{array}{l}\text { Silica coated-magnetic } \\
\text { nanoparticles }\end{array}$ & 2,6-Diaminopyridine & $\mathrm{Cu}(\mathrm{II})$ and $\mathrm{Zn}(\mathrm{II})$ & [37] \\
\hline 5. & Magnetic nanoparticles & $\begin{array}{l}\text { (3-Aminopropyl)-triethoxysilane (APTES) and } \\
\text { glutaraldehyde (GA) }\end{array}$ & $\mathrm{Cu}(\mathrm{II})$ & {$[39]$} \\
\hline 6. & Magnetic nanoparticles & Dithizone & $\begin{array}{l}\mathrm{Cr}(\mathrm{III}), \mathrm{Cu}(\mathrm{II}), \mathrm{Pb}(\mathrm{II}) \\
\mathrm{Hg}(\mathrm{II}) \text { and } \mathrm{Zn}(\mathrm{II})\end{array}$ & [40] \\
\hline 7. & $\begin{array}{l}\text { Gold nanoparticles loaded in } \\
\text { activated carbon }\end{array}$ & Bis-(4-methoxy salicylaldehyde)-1,2-phenylenediamine & $\begin{array}{l}\mathrm{Co}(\mathrm{II}), \mathrm{Cu}(\mathrm{II}), \mathrm{Ni}(\mathrm{II}) \\
\mathrm{Fe}(\mathrm{II}), \mathrm{Pb}(\mathrm{II}) \text { and } \mathrm{Zn}(\mathrm{II})\end{array}$ & [1] \\
\hline 8. & $\begin{array}{l}\text { Mesoporous silica } \\
\text { nanoparticles }\end{array}$ & $\begin{array}{l}N, N \text { (octane-1,8-diylidene)di(2-hydroxy-3, } \\
\text { 5-dimethyl-aniline) }\end{array}$ & $\mathrm{Pd}(\mathrm{II})$ & [42] \\
\hline 9. & Halloysite nanotubes & Murexide & $\mathrm{Pd}(\mathrm{II})$ & [3] \\
\hline
\end{tabular}


Fig. 1 Sequence of events in the preparation of chelated nanostructured materials

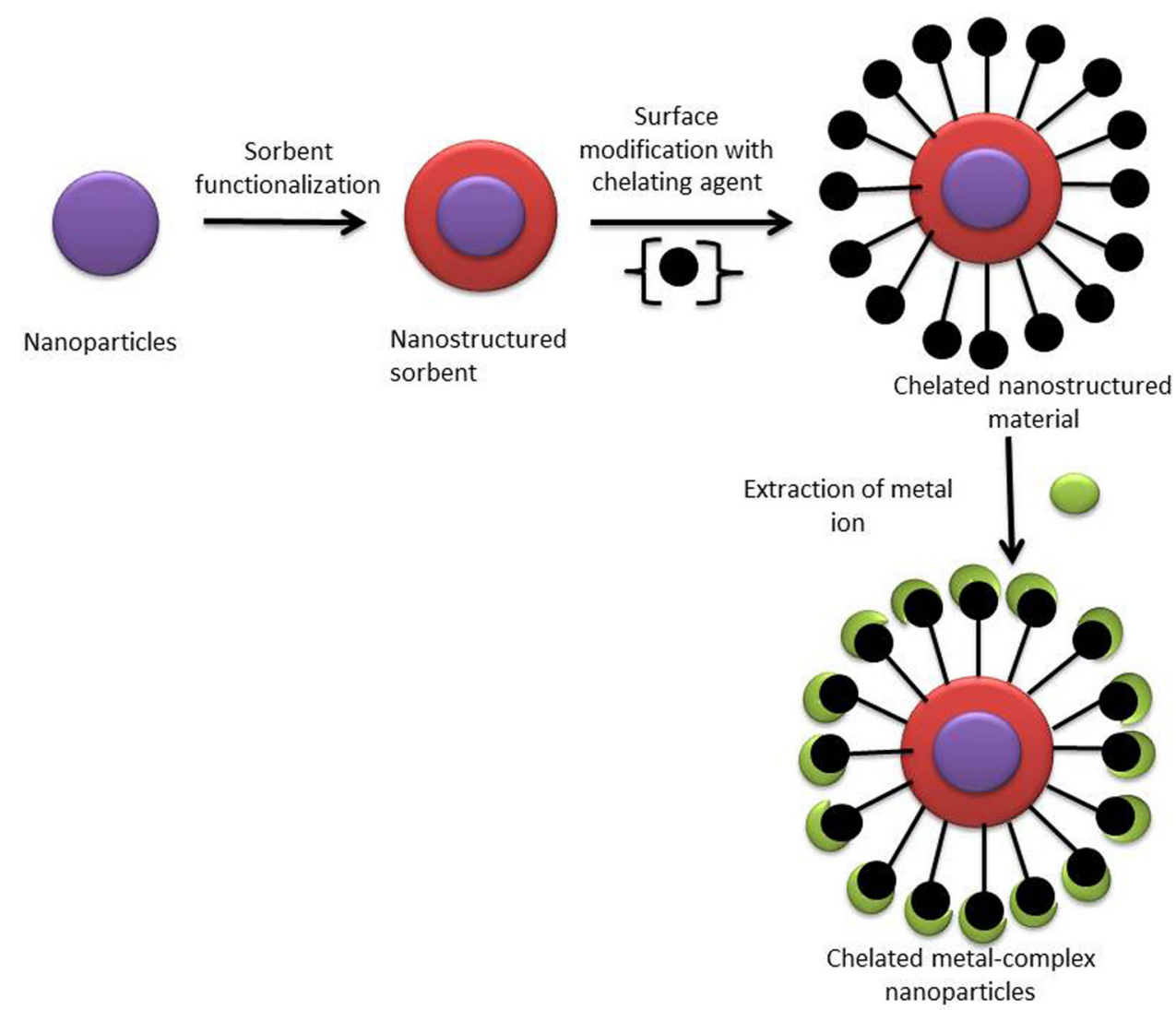

Table 2 Various chelated nanostructured organic sorbent-support systems for extraction of metal ions

\begin{tabular}{|c|c|c|c|c|}
\hline $\begin{array}{l}\text { S. } \\
\text { no. }\end{array}$ & Support material & Ligand & Selective for following metal ion & References \\
\hline 1. & $\begin{array}{l}\text { Multiwalled carbon } \\
\text { nanotubes }\end{array}$ & 2-(2-Hydroxy-5-nitrophenyl)-4,5-diphenyl imidazole & $\begin{array}{l}\mathrm{Co}(\mathrm{II}), \mathrm{Cu}(\mathrm{II}), \mathrm{Ni}(\mathrm{II}), \mathrm{Fe}(\mathrm{II}) \\
\mathrm{Pb}(\mathrm{II}) \text { and } \mathrm{Zn}(\mathrm{II})\end{array}$ & {$[6]$} \\
\hline 2. & $\begin{array}{l}\text { Multiwalled carbon } \\
\text { nanotubes }\end{array}$ & $\begin{array}{l}(E)-N 1 \text {-(4-nitro-benzylidene)- } N 2-(2-((E)-4- \\
\text { nitrobenzylideneamino)ethyl) ethane-1,2-diamine }\end{array}$ & $\mathrm{Cu}(\mathrm{II}), \mathrm{Zn}(\mathrm{II}), \mathrm{Pb}(\mathrm{II})$ and $\mathrm{Cd}(\mathrm{II})$ & {$[45]$} \\
\hline
\end{tabular}

silica-coated $\mathrm{Fe}_{3} \mathrm{O}_{4}$ nanoparticles with 2,6-diaminopyridine. The stereochemical interactions of two amino and one pyridine ring with target ion resulted in selective coordination for $\mathrm{Cu}$ (II) and $\mathrm{Zn}$ (II). Since the adsorption capacity of these two ions is comparable, the magnetic nanoparticles were of great use because of high selectivity and magnetically separable property [37]. Huang and $\mathrm{Hu}$ synthesized silica-coated magnetic nanoparticles (SCMNPs) and modified them with $\gamma$-mercaptopropyltrimethoxysilane ( $\gamma$-MPTMS) for extraction of trace amounts of $\mathrm{Cd}, \mathrm{Cu}, \mathrm{Hg}$ and $\mathrm{Pb}$. For the recovery of metal, magnetic nanoparticles were separated easily using an external magnetic field. This method provided high enrichment factors and rapid adsorption of metals under study [38].
Ozmen et al. used a quick and easy metal separation process by preparing (3-aminopropyl)-triethoxysilane (APTES) and glutaraldehyde (GA) and modified them with $\mathrm{Fe}_{3} \mathrm{O}_{4}$ magnetic nanoparticles. These nanoparticles were then used for effective removal of $\mathrm{Cu}(\mathrm{II})$ from wastewater in acidic $\mathrm{pH}$ range (4.0-5.3). This separation process was completed in around $15 \mathrm{~min}$ and thus proved to be efficient for this purpose [39].

$\mathrm{Hu}$ et al. modified the surface of magnetic $\mathrm{Fe}_{3} \mathrm{O}_{4}$ nanoparticles with dithizone, mercaptopropyltrimethoxysilane and bismuthiol-II. These modified magnetic nanoparticles proved to be efficient for the fast preconcentration and determination of trace amount of $\mathrm{Cr}$ (III), $\mathrm{Cu}(\mathrm{II}), \mathrm{Pb}(\mathrm{II}), \mathrm{Hg}$ (II) and $\mathrm{Zn}$ (II) in environmental and biological samples [38, 40, 41]. 
Organic monolayer-coated metal nanoparticles have proved to be good sorbents due to chemical stability and selectivity. Karimipour et al. synthesized gold nanoparticles loaded in activated carbon (Au-NP-AC) and modified it by bis-(4-methoxy salicylaldehyde)-1,2-phenylenediamine (BMSAPD). This sorbent was used for enrichment and preconcentration of trace amounts of $\mathrm{Co}^{2+}, \mathrm{Cu}^{2+}, \mathrm{Ni}^{2+}$, $\mathrm{Fe}^{2+}, \mathrm{Pb}^{2+}$ and $\mathrm{Zn}^{2+}$ ions via complexation by BMSAPD ligand. They retained metal ions by elution with $\mathrm{HNO}_{3}$ [1].

\section{Silica nanoparticles}

Awual et al. prepared a nano-conjugate adsorbent (NCA) by anchoring an organic ligand $N, N$ (octane-1,8-diylidene)di(2-hydroxy-3,5-dimethyl-aniline) (DHDM) onto mesoporous silica by direct immobilization approach. DHDM has strong electrostatic interactions with hydroxylcontaining mesoporous surface. This sorbent exhibited distinct colour based on charge transfer on sorption of $\mathrm{Pd}(\mathrm{II})$ in both solid and liquid states. Pd(II) adsorption was found to increase sharply on increasing contact time and concentration of ligand [42].

\section{Halloysite nanotubes}

Besides mineral oxides, halloysite (2-layered alumino silicate clay mineral) nanotubes have also been used for the purpose of metal extraction. Since halloysite nanotubes (HNTs) have reactive hydroxyl groups on the surface, their modification with some organic compound tends to increase the sorption selectivity of metal ions. Li et al. synthesized and used murexide functionalized HNTs for selective extraction of $\mathrm{Pd}(\mathrm{II})$. Acidic environment was provided for protonation of binding sites of chelating agent, thus favouring selective adsorption of $\mathrm{Pd}(\mathrm{II})$. Pd(II) was retained on the column at $\mathrm{pH} 1.0$ and quantitatively eluted by $2.5 \mathrm{~mL}$ of $0.01 \mathrm{~mol} \mathrm{~L}^{-1} \mathrm{HCl}-3 \%$ thiourea solution at a flow rate of $2.0 \mathrm{~mL} \mathrm{~min}^{-1}$ [3].

\section{Organic-based sorbents}

Multiwalled carbon nanotubes (MWCNTs) have high tensile strengths and great thermal and chemical stability. Due to high surface area and large micropore volume, these are good adsorbents for metal ion extraction [43, 44].

Ghaedi et al. modified MWCNTs with 2-(2-hydroxy-5nitrophenyl)-4,5-diphenyl imidazole for enrichment of trace amounts of various ions. To obtain highly efficient metal ions, optimization of the influence of variables including $\mathrm{pH}$, amount of ligand and solid phase, type and condition of eluent and common coexisting ions was done. The metal ions $\left(\mathrm{Co}^{2+}, \mathrm{Cu}^{2+}, \mathrm{Ni}^{2+}, \mathrm{Fe}^{2+}, \mathrm{Pb}^{2+}\right.$ and $\left.\mathrm{Zn}^{2+}\right)$ were then desorbed using nitric acid [6].
Soylakab et al. modified MWCNTs with (E)-N1-(4-nitrobenzylidene)-N2-(2-((E)-4-nitrobenzylideneamino)ethyl) ethane-1,2-diamine (NBNBAEED). Due to the existence of donating nitrogen atom as well as $-\mathrm{NH}$ group in NBNBAEED, both the stability and selectivity of its $\mathrm{Cu}^{2+}$, $\mathrm{Zn}^{2+}, \mathrm{Pb}^{2+}$ and $\mathrm{Cd}^{2+}$ ion complex over other metal ions increased, thus providing fast adsorption and high metal recovery [45].

\section{Porous and chelated nanostructured materials as reusable catalysts for diverse organic reactions}

The photocatalytic reactions occur mainly on surface of a catalyst. Since nanostructures provide a large surface-tovolume ratio, they show high photocatalytic activity [46]. Since metal nanoparticles can easily aggregate in catalytic reactions and hence can decrease the available surface area, metal nanoparticles are modified with various sorbents. The chelated nanostructured materials have been used for catalysing various organic reactions as explained below.

\section{Reduction reactions}

Both metal and metal oxides modified with suitable chelating agents have been used as catalysts in reduction reactions. Du and He immobilized gold nanoparticles into previously fabricated amino-functionalized silica nanoparticles with centreradially hierarchical mesopores ( $\mathrm{Au}-\mathrm{NH}_{2}-\mathrm{HMSNs}$ ) and used them as catalyst in catalytic reduction of 2-nitroaniline (Fig. 2). The centre-radially hierarchical mesopores enhanced diffusion of guest molecules, thus providing excellent catalytic activity and stability [47].

Jiang et al. prepared nano-Ni core mesoporous-silica shell (NCMSS) particles using EDTA as the chelating agent $\left(\mathrm{Ni} @ \mathrm{SiO}_{2} /\right.$ EDTA) and used them as a catalyst for reduction of 4-nitrophenol to 4-aminophenol in the presence of excess amount of $\mathrm{NaBH}_{4}$ (Fig. 3). The reaction was found to show pseudo-first order kinetics with respect to 4-nitrophenol. Since only a small amount of catalyst provides great results, NCMSSs have a great potential in catalytic fields in future [26].

Sharma et al. immobilized copper(II) acetylacetone complex over amino functionalized silica@magnetite

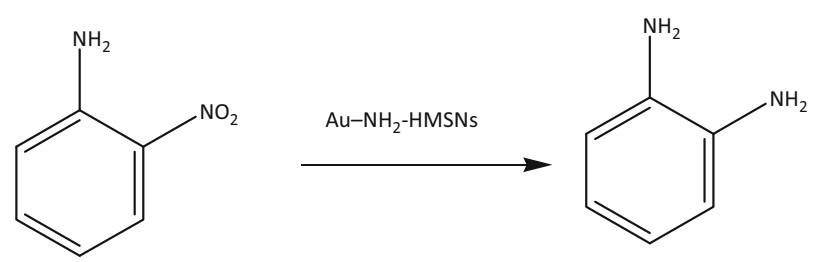

Fig. 2 Reduction of 2-nitroaniline using $\mathrm{Au}-\mathrm{NH}_{2}-\mathrm{HMSNs}$ 
nanoparticles (Cu-acac@ $\left.\mathrm{Am}-\mathrm{Si}-\mathrm{Fe}_{3} \mathrm{O}_{4}\right)$ for catalytic reduction of nitro group using $\mathrm{NaBH}_{4}$ as source of hydrogen (Fig. 4). They also studied the kinetics for reduction reaction of $o$-nitroaniline to benzenediamine. Since nano-catalytic system can be easily recovered using magnets, they can be reused for multiple cycles [48].

Negroa et al. prepared three $\mathrm{Fe}-\mathrm{N}$ non-noble electrocatalysts using networked graphitic structures as support. They found that catalysts with higher cobalt and iron content showed maximum oxygen reduction reaction (ORR) activity. This electrocatalyst showed promising applications in low-temperature fuel cells [49].

Veerakumara et al. synthesized gold nanoparticles (AuNPs) using highly branched polyethylenimine (PEI) and acylated PEI as the chelating agents. These modified gold nanoparticles were found to be excellent catalyst for selective reduction of nitro compounds in presence of sodium borohydride (Fig. 5). This catalyst was found to be stable for a long time without any provided support [50].

Oh et al. synthesized nitrogen-modified carbon nanofibres by pyrolysis of cobalt, polypyrrole (PPy) using ethylenediamine (ED) as the chelating agent for obtaining stable oxygen reduction catalysts. They found that combined use of PPy and ED increased activity and stability of catalyst by increasing total nitrogen contents [51].

\section{Photocatalytic degradation reactions}

Yang et al. synthesized $\mathrm{YMn}_{2} \mathrm{O}_{5}$ nanoparticles using different chelating agents. They found that $\mathrm{YMn}_{2} \mathrm{O}_{5}$ nanoparticles prepared using citric acid exhibited slightly high photocatalytic activity than the sample prepared using EDTA as the chelating agent. These nanoparticles showed excellent photocatalytic activity for oxidative decomposition of methyl red under UV and visible light irradiation [27].

Zhanga et al. synthesized $\mathrm{Bi}_{2} \mathrm{Fe}_{4} \mathrm{O}_{9}$ nanoparticles using different chelating agents and observed their photocatalytic activity. The use of EDTA favoured the synthesis of relatively small particle sized $\mathrm{Bi}_{2} \mathrm{Fe}_{4} \mathrm{O}_{9}$ nanoparticles. These nanoparticles were found to exhibit excellent photocatalytic degradation of methyl red [46].

Makarova et al. modified surface of nanocrystalline titanium dioxide with specific chelating agents for

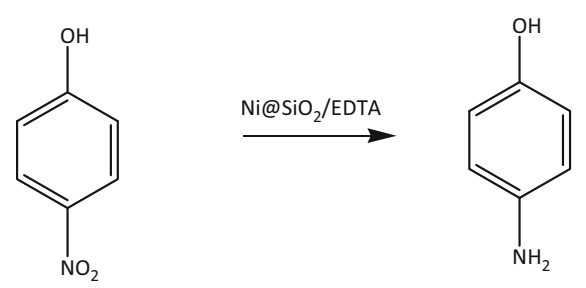

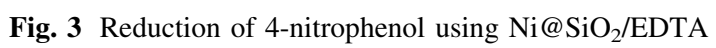

\section{Ar- $\mathrm{NO}_{2} \stackrel{\mathrm{Cu}-\mathrm{acac} @ \mathrm{Am}-\mathrm{Si}-\mathrm{Fe}_{3} \mathrm{O}_{4}}{\longrightarrow} \quad \mathrm{Ar}-\mathrm{NH}_{2}$}

Fig. 4 Reduction of nitro group using $\mathrm{Cu}-\mathrm{acac} @ \mathrm{Am}-\mathrm{Si}-\mathrm{Fe}_{3} \mathrm{O}_{4}$

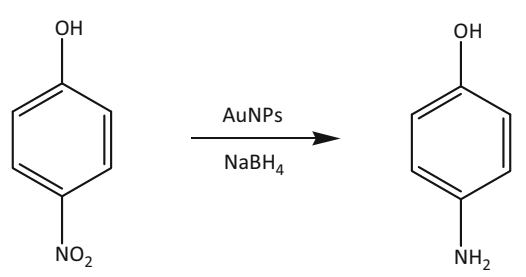

Fig. 5 Selective reduction of nitro compounds using AuNPs/PEI

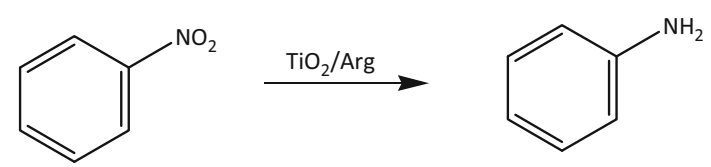

Fig. 6 Reduction of nitrobenzene using $\mathrm{TiO}_{2} / \mathrm{Arg}$

photochemical reduction of nitrobenzene. The modification was done using arginine, lauryl sulphate and salicylic acid (Fig. 6). It was found that arginine-modified $\mathrm{TiO}_{2}\left(\mathrm{TiO}_{2} /\right.$ Arg) was more stable and showed better photocatalytic decomposition as compared to other chelating agents [52].

Wang et al. synthesized $\mathrm{BaTiO}_{3}$ nanoparticles using acetylacetone and citric acid as chelating agents. These nanoparticles were tested for their photocatalytic activities for removal of humic acid from water. The tetragonal phase $\mathrm{BaTiO}_{3}$ nanoparticles were found to be excellent photocatalysts for decomposition of organic pollutants [53].

Habibi and Mokhtari fabricated novel sulphur-modified niobium (V) oxide nanoparticles by a modified sol-gel method. A very stable sol-containing niobium $(\mathrm{V})$ chloride and oxalic acid were used with isopropanol as chelating agent and thiourea as sulphur source. Unlike unmodified niobium (V) nanoparticles, the doped ones induced charge transfer across the niobium pentoxide interface. These nanoparticles can be suitably used as semiconductor photocatalysts and for visible light sensitization [54]. Sun et al. synthesized nano-sized $\mathrm{BiVO}_{4}$ by a hydrothermal process in the presence of EDTA as chelating agent. With reduction of hydrothermal temperature and increase in concentration of EDTA, the size of $\mathrm{BiVO}_{4}$ nanoparticles decreases. This sample showed a high photocatalytic activity for degradation of phenol solution [55].

Saien and Mesgari prepared nitrogen-doped $\mathrm{TiO}_{2}$ nanoparticles using hematoporphyrin as the support material. These nanocomposites exhibited highly efficient visible-light photocatalytic activity for degradation of methyl 
orange. These nanocomposites can be reused again without any loss in its activity [56].

\section{Hydrogenation/dehydrogenation reactions}

Tianbin et al. synthesized Zr-based metal organic frameworks $(\mathrm{Zr} / \mathrm{MOF})$ that contained both mesopores and micropores by the reaction of 1,4-benzenedicarboxylic acid $\left(\mathrm{H}_{2} \mathrm{BDC}\right)$ and $\mathrm{ZrOCl}_{2} \cdot 8 \mathrm{H}_{2} \mathrm{O}$ using citric acid as the chelating agent and cetyltrimethylammonium bromide (CTAB) as surfactant. The Ru@Zr/MOF (ruthenium nanoparticles embedded on $\mathrm{Zr}$-based MOF) catalyst was prepared in supercritical $\mathrm{CO}_{2}$-methanol solution. This resulted in $\mathrm{Ru}$ nanoparticles with small size that were uniformly supported in the $\mathrm{Zr}-\mathrm{MOF}$ unlike in the case of immobilization where particles were of larger size. This catalyst showed significant catalytic activity in hydrogenation of benzene and its derivatives (Fig. 7) [57].

Qureshi et al. prepared Pd nanoparticles supported on porous silica nanospheres KCC-1. The silica-supported Pd nanocatalysts were prepared by modification of the supports with 3-aminopropyltrimethoxysiliane (3-APTES). 3-APTES acted as binding agent for $\mathrm{PdCl}_{2}$ with the aim of obtaining well-spaced and uniformly dispersed Pd atoms on the silica surface. These proved to be efficient, chemoselective catalysts for hydrogenation of alkenes and $\alpha, \beta$-unsaturated carbonyl compounds (Fig. 8). A comparison between Pd nanoparticles supported on KCC-1 and those prepared on traditional mesoporous silica materials under similar conditions was done. It was found that the nanoparticles on KCC-1 showed excellent catalytic activity and particle dispersion. This catalyst can be reused many times without any significant loss in its catalytic activity [58].

\section{Oxidation reactions}

Sharma and Sharma immobilized palladium complex on silica nanospheres functionalized with 3-aminopropyltriethoxysilane ( $\mathrm{SiO}_{2} @$ APTES@Pd-FFR).This nano-catalyst was found to be highly selective for oxidative amination of aldehydes (Fig. 9). The high activity of this nanocatalyst provided ease in time and cost along with high yield and enhanced dispersion. Since this catalyst provided high turnover frequencies and can be easily reused without loss in its

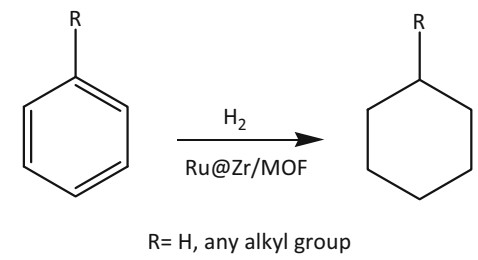

Fig. 7 Hydrogenation of benzene by Ru@Zr/MOF

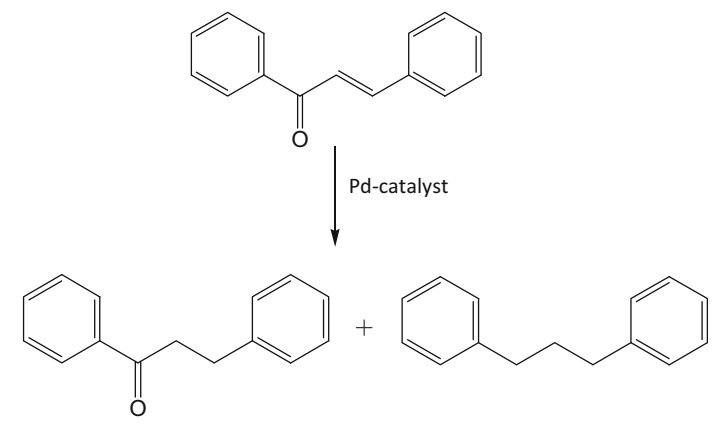

Fig. 8 Hydrogenation of alkenes and $\alpha, \beta$-unsaturated carbonyl compounds

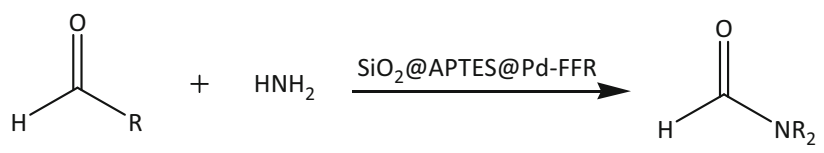

Fig.9 Oxidative amination of aldehydes using $\mathrm{SiO}_{2} @$ APTES@PdFFR

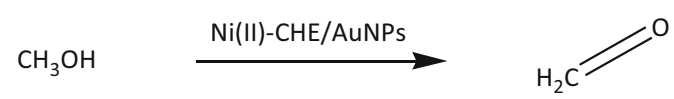

Fig. 10 Electrocatalytic oxidation of methanol by $\mathrm{Ni}(\mathrm{II})-\mathrm{CHE} /$ AuNPs

activity, the catalyst proved to be useful for industrial and environmental applications [59].

Gholivand and Azadbakht prepared nano-structured $\mathrm{Ni}(\mathrm{II})$-chelidamic acid-modified gold nanoparticles (Ni(II)/ CHE/AuNPs) by electrodeposition of Ni(II)/CHE complex on the surface of the AuNP-Au electrode in alkaline solution. This catalyst was tested for electrocatalytic oxidation (Fig. 10) and determination of methanol. This electrode proved to be an excellent catalyst for oxidation of methanol [60].

Kumar et al. prepared nano-spinel $\mathrm{CuAl}_{2} \mathrm{O}_{4}$ and investigated the effect of ethylenediamine addition. This catalyst was found to have high surface area, low activation energy and high porosity. Due to more number of active sites at low temperature, it is highly active for selective oxidation of benzyl alcohol to benzaldehyde (Fig. 11). This explained that addition of ethylenediamine during preparation process enhanced the catalytic activity of copper aluminate [61].

Also, Cruz et al. also used self-prepared copper(II) complexes supported on hybrid mesoporous SBA-15 functionalized with imidazole ionic liquid and an amino chelate ligand, as efficient catalyst for selective oxidation of benzyl alcohol to benzaldehyde in aqueous phase [62].

Pandey et al. prepared stable $\mathrm{CuO}$ nanoparticles immobilized on resin in presence of cyclodextrin as an 


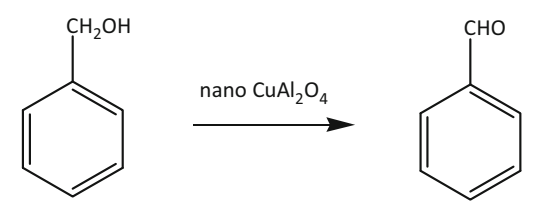

Fig. 11 Selective oxidation of benzyl alcohol using nano- $\mathrm{CuAl}_{2} \mathrm{O}_{4}$ spinel

organic support material. These nanoparticles were found to be effective catalyst for liquid phase oxidation of alcohols to aldehydes. The catalytic activity was found to be better than the earlier used $\mathrm{Cu}(0)$ nanocomposites [63].

\section{Coupling reactions}

Dutta and Sarkar immobilized palladium nanoparticles on chemically modified silica gel which were stabilized by encapsulation through PEG tentacles. These nanoparticles were prepared by reaction of modified silica gel with potassium tetrachloropalladate(II) in presence of an acyl metal salt of a Fischer carbene complex. This nanocatalyst proved to be an efficient heterogeneous catalyst for Suzuki, Stille and Sonogashira cross-coupling reactions (Fig. 12) [64].

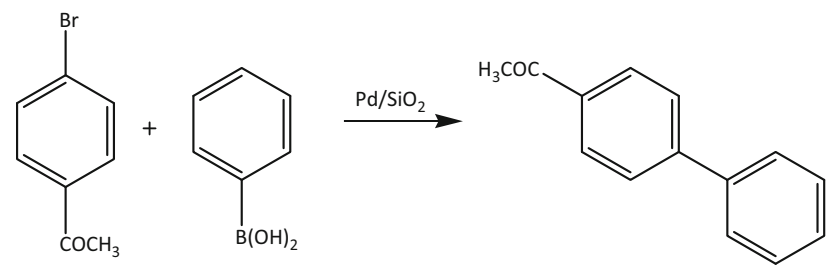

Fig. 12 Coupling reaction of 4-bromoacetophenone with phenylboronic acid using $\mathrm{Pd} @ \mathrm{SiO}_{2} / \mathrm{PEG}$

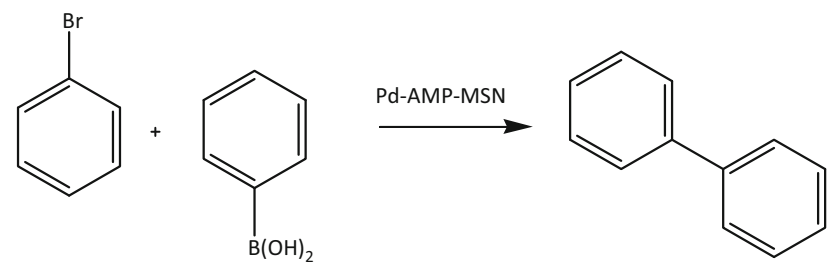

Fig. 13 Suzuki-Miyaura cross-coupling reaction of aryl halides with phenylboronic acids using Pd-AMP-MSN
$\mathrm{He}$ et al. synthesized a novel palladium(II) organometallic catalyst by coordinating $\operatorname{Pd}(\mathrm{II})$ ions with $\mathrm{PPh}_{2}$-functionalized mesoporous silica nanospheres. Unlike the ones previously prepared by traditional methods, this catalyst exhibited higher activity and selectivity for water-medium $\mathrm{C}-\mathrm{C}$ coupling reactions and could be used repeatedly for various cycles [65]. Mondal et al. prepared palladium(II) 2-aminopyridine complex in situ by co-condensation reaction of tetraethylorthosilicate (TEOS) with ((chloromethyl)phenylethyl)trimethoxysilane (CMPETMS) using CTAB as the structure directing agent and supported it on mesoporous silica nanospheres (Pd-AMPMSN). It was shown to have high catalytic activity for Suzuki-Miyaura cross-coupling reactions of aryl iodides, aryl bromides and also aryl chlorides with phenylboronic acids in water medium with high yields (Fig. 13) [66].

Isfahani et al. immobilized palladium nanoparticles on nanosilica triazine dendritic polymer ( $\mathrm{Pd}-\mathrm{nSTDP})$. These were found to be efficient catalysts for Sonogashira cross coupling of aryl halides with aromatic and aliphatic terminal alkynes where water was used as solvent (Fig. 14). This catalytic system can also be used for preparation of Vand star-shaped molecules and the catalyst can be recovered and reused [67].

Vaghei et al. synthesized novel SBA-15/AO/Pd(II) nanocatalyst by grafting of amidoxime on SBA-15 and deposition of palladium chlorides. This catalyst, under mild conditions, was found to have high catalytic activity for the Suzuki-Miyaura cross-coupling reaction of aryl halides with phenylboronic acid (Fig. 15) [68].

Naghipour and Fakhri prepared Pd-based nanocatalyst supported on magnetite nanoparticles using chitosan-Schiff base as the chelating agent. This catalyst $\left(\mathrm{Pd} / \mathrm{Fe}_{3} \mathrm{O}_{4} @-\right.$ chitosan-Schiff base) in mild experimental conditions was found to be highly efficient for Suzuki-Miyaura and HeckMizoroki $\mathrm{C}-\mathrm{C}$ coupling reactions. Also, since the catalyst is supported on magnetite nanoparticles, it can be easily recovered magnetically [69].

\section{Miscellaneous reactions}

Nyalosaso et al. prepared aluminium-derived silica monodisperse nanospheres (Al-MSS-22) by a one-step synthesis-functionalization method and its surface
Fig. 14 Sonogashira cross coupling of aryl halides with terminal alkynes using PdnSTDP as catalyst<smiles>C#Cc1ccccc1</smiles> 
Fig. 15 Suzuki-Miyaura crosscoupling of aryl halides with phenylboronic acid using SBA$15 / \mathrm{AO} / \mathrm{Pd}(\mathrm{II})$

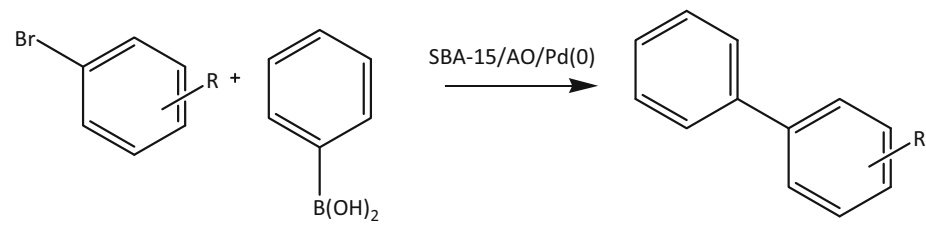

$\mathrm{Li}$ et al. used aqueous phosphine-Rh complexes immobilized on non-porous fumed-silica nanoparticles $\left(\mathrm{HRh}(\mathrm{CO})(\mathrm{TPPTS})_{3} @ \mathrm{SiO}_{2}\right)$ for their catalytic activity in higher olefin hydroformylation. They showed that the structure and hydration of support material are the two important factors in hydroformylation reaction. It was found that addition of basic alkali metal salts in the system favoured hydroformylation of 1-hexene [72].

Chen et al. synthesized dialkylaminopyridine-functionalized mesoporous silica nanospheres (DMAP-MSN). This nanocatalyst showed high turnover frequency for BaylisHillman, acylation and silylation reactions and could also serve as efficient catalyst for various other nucleophilic reactions (Fig. 17) [73].

Peng et al. synthesized acid-base bi-functionalized mesoporous silica nanoparticles. These nanoparticles were

Fig. 16 Esterification of ethanoic acid with alcohols/polyols using Al-MSS-22 as catalyst

Fig. 17 a Baylis-Hillman reaction using DMAP-MSN catalyst. b Acylation reaction using DMAP-MSN catalyst (a)<smiles>[R]C(=O)C=C</smiles>

DMAP-MSN<smiles>[R]C(=O)C(=C)C([R])O</smiles><smiles>[R]C(=O)C(=C)CC(C([R])=O)C([R])O</smiles><smiles>[R]C(=O)CCOC([R])C(=C)C([R])=O</smiles>

(b)<smiles>CC(=O)OC(C)=O</smiles><smiles>[R6]C(C)=O</smiles> 
studied for catalytic activity for one-pot conversion of 5-hydroxymethylfurfural (HMF) in an ionic liquid by using cellulose, cellobiose, glucose and fructose as starting materials. It was found that these nanoparticles showed high catalytic activity towards cellulose-to-HMF conversion (Fig. 18) [74].

Tang et al. immobilized salicylaldimine cobalt complexes on mesoporous silica nanoparticles (Co-MSN/
Fig. 18 Scheme for conversion of cellulose to 5-HMF

Fig. 19 a Friedel-Crafts reaction using $\mathrm{Zr}(\mathrm{IV})$ HMNQ@ASMPs catalyst. b Knoevenagel condensation reaction using $\mathrm{Zr}(\mathrm{IV})-$ HMNQ@ASMPs catalyst. c Pechmann condensation reaction using $\mathrm{Zr}(\mathrm{IV})-$ HMNQ@ASMPs catalyst

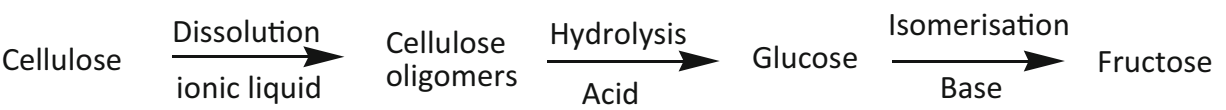

Hydrolysis Acid

5-HMF (a)<smiles>[R]c1ccccc1C=O</smiles>

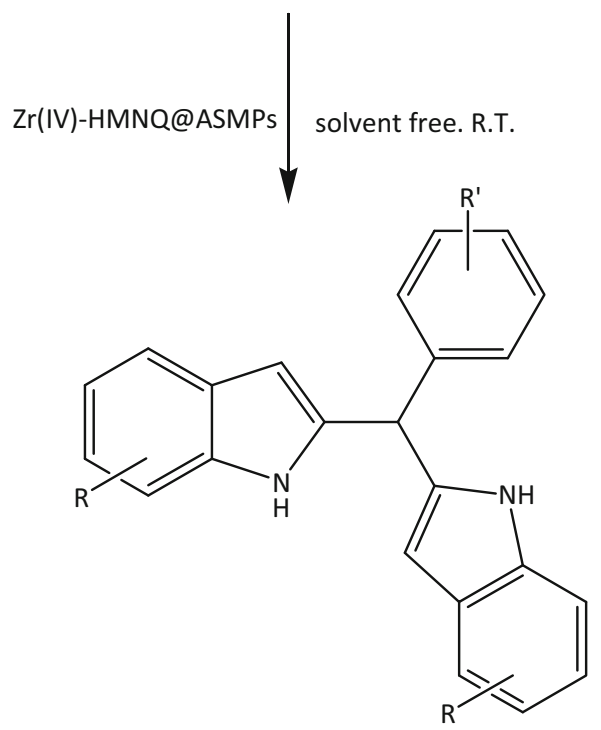

(b)<smiles>[R]c1ccccc1C=O</smiles>

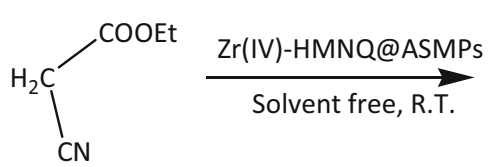<smiles>[R]c1ccc(C=C(C#N)C(=O)OCC)cc1</smiles>

(c)<smiles>[R]c1cccc2c1C(C)=CC(=O)C2</smiles> 
<smiles>[Z6]/C(O)=C\C(=O)[AlH2]</smiles>

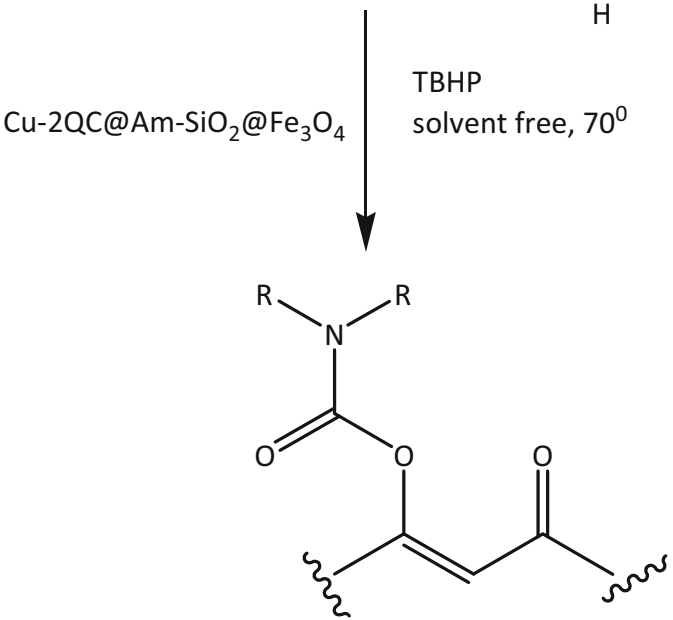

Fig. 20 Synthesis of carbamates via $\mathrm{C}-\mathrm{H}$ activation of formamides using $\mathrm{Cu}-2 \mathrm{QC} @ \mathrm{Am}-\mathrm{SiO}_{2} @ \mathrm{Fe}_{3} \mathrm{O}_{4}$ catalyst

MAO). These nanocatalysts showed higher activity than existing homogeneous analogue and proved to be highly efficient for catalytic polymerization of 1,3-butadiene [75].

Sharma et al. synthesized zirconium (IV)-modified@amine functionalized silica nanocomposites by grafting of 3-hydroxy-2-methyl-1,4-napthoquinone covalently (Zr(IV)-HMNQ@ASMPs). These catalysts were found to be efficient for Friedel-Crafts, Knoevenagel and Pechmann condensation reactions (Fig. 19). The catalyst provided high selectivity and could be reused for a number of cycles [76].

Sharmaet al. immobilized quinolone-2-carboxyaldehyde on amine functionalized silica-coated magnetite nanoparticles. This was followed by metallation with copper acetate (Cu-2QC@ $\left.\mathrm{Am}-\mathrm{SiO}_{2} @ \mathrm{Fe}_{3} \mathrm{O}_{4}\right)$. This catalyst showed efficient activity for synthesis of carbamates via $\mathrm{C}-$ $\mathrm{H}$ activation of formamides (Fig. 20). The catalyst was easily recovered and could be reused for multiple cycles [77].

\section{Conclusions}

Nanostructured modified chelating agents prepared by functionalization method have been discussed in view of applications in the metal extraction and catalysis. With their controllable morphology, particle size and incorporation of active sites at the surface through synthesis-functionalization procedure, desired properties of nanostructured chelating agents can be easily achieved. Such advanced functionalized
Table 3 Various nanostructured chelating sorbents as nanocatalysts for diverse organic reactions

\begin{tabular}{|c|c|c|c|}
\hline S. no. & Nanocatalyst & Organic reaction & Reference \\
\hline 1. & $\mathrm{Au}-\mathrm{NH}_{2}-\mathrm{HMSNs}$ & $\begin{array}{l}\text { Reduction of } \\
\text { 2-nitroaniline }\end{array}$ & [47] \\
\hline 2. & $\mathrm{Ni@SiO_{2 } / E D T A}$ & $\begin{array}{l}\text { Reduction of } \\
\text { 4-aminophenol }\end{array}$ & [26] \\
\hline 3. & $\begin{array}{l}\mathrm{Cu}-\mathrm{acac} @ \mathrm{Am}-\mathrm{Si}- \\
\mathrm{Fe}_{3} \mathrm{O}_{4}\end{array}$ & $\begin{array}{l}\text { Reduction of aromatic } \\
\text { nitro groups }\end{array}$ & [48] \\
\hline 4. & $\begin{array}{l}\mathrm{Fe}-\mathrm{N} \text { non-noble } \\
\text { electrocatalysts }\end{array}$ & Oxygen reduction reaction & [49] \\
\hline 5. & AuNPs/PEI & $\begin{array}{l}\text { Reduction of nitro } \\
\text { compounds in presence } \\
\text { of } \mathrm{NaBH}_{4}\end{array}$ & {$[50]$} \\
\hline 6. & $\begin{array}{l}\mathrm{N} \text {-modified carbon } \\
\text { nanofibres/ED }\end{array}$ & Oxygen reduction reaction & [51] \\
\hline 7. & $\mathrm{Bi}_{2} \mathrm{Fe}_{4} \mathrm{O}_{9} / \mathrm{EDTA}$ & $\begin{array}{l}\text { Photocatalytic degradation } \\
\text { of methyl red }\end{array}$ & [46] \\
\hline 8. & $\mathrm{BaTiO}_{3} / \mathrm{acac}$ or CA & $\begin{array}{l}\text { Photocatalytic removal of } \\
\text { humic acid from water }\end{array}$ & [53] \\
\hline 9. & $\mathrm{YMn}_{2} \mathrm{O}_{5} / \mathrm{CA}$ & $\begin{array}{l}\text { Oxidative decomposition } \\
\text { of methyl red }\end{array}$ & [27] \\
\hline 10. & $\begin{array}{l}\mathrm{Nb}_{2} \mathrm{O}_{5} @ \mathrm{~S} / \\
\text { isopropanol }\end{array}$ & $\begin{array}{r}\text { Semiconductor } \\
\text { photocatalyst }\end{array}$ & [54] \\
\hline 11. & $\mathrm{BiVO}_{4} / \mathrm{EDTA}$ & $\begin{array}{l}\text { Photocatalytic degradation } \\
\text { of phenol solution }\end{array}$ & [55] \\
\hline 12. & $\begin{array}{l}\mathrm{N} \text {-doped } \mathrm{TiO}_{2} / \\
\text { hematoporphyrin }\end{array}$ & $\begin{array}{l}\text { Photocatalytic degradation } \\
\text { of methyl orange }\end{array}$ & [56] \\
\hline 13. & Ru@Zr/MOF & $\begin{array}{l}\text { Hydrogenation of benzene } \\
\text { and its derivatives }\end{array}$ & [57] \\
\hline 14. & $\mathrm{Pd} @ \mathrm{SiO}_{2} / 3$-APTES & $\begin{array}{l}\text { Hydrogenation of alkenes } \\
\text { and } \alpha, \beta \text {-unsaturated } \\
\text { carbonyl compounds }\end{array}$ & [58] \\
\hline 15. & $\begin{array}{l}\mathrm{SiO}_{2} @ \text { APTES@Pd- } \\
\text { FFR }\end{array}$ & $\begin{array}{l}\text { Oxidative amination of } \\
\text { aldehydes }\end{array}$ & [59] \\
\hline 16. & $\mathrm{Ni}(\mathrm{II})-\mathrm{CHE} / \mathrm{AuNPs}$ & Oxidation of methanol & [60] \\
\hline 17. & $\begin{array}{l}\text { Nano- } \mathrm{CuAl}_{2} \mathrm{O}_{4} \\
\text { spinel }\end{array}$ & $\begin{array}{l}\text { Selective oxidation of } \\
\text { benzyl alcohol to } \\
\text { benzaldehyde }\end{array}$ & [61] \\
\hline 18. & $\begin{array}{l}\text { Cu@SBA-15/amino } \\
\text { alcohol chelate } \\
\text { ligand }\end{array}$ & $\begin{array}{l}\text { Selective oxidation of } \\
\text { benzyl alcohol to } \\
\text { benzaldehyde }\end{array}$ & [62] \\
\hline 19. & CuO@cyclodextrin & Alcohol oxidation & [63] \\
\hline 20. & $\mathrm{Pd} @ \mathrm{SiO}_{2} / \mathrm{PEG}$ & $\begin{array}{l}\text { Suzuki, Stille and } \\
\text { Sonogashira cross- } \\
\text { coupling reactions }\end{array}$ & {$[64]$} \\
\hline 21. & $\mathrm{Pd} @ \mathrm{SiO}_{2} / \mathrm{PPh}_{2}$ & $\begin{array}{l}\text { Water-medium } \mathrm{C}-\mathrm{C} \\
\text { coupling reactions }\end{array}$ & [65] \\
\hline 22. & Pd-AMP-MSN & $\begin{array}{l}\text { Suzuki-Miyaura coupling } \\
\text { reactions of aryl halides } \\
\text { with phenylboronic } \\
\text { acids }\end{array}$ & [66] \\
\hline 23. & Pd-nSTDP & $\begin{array}{l}\text { Sonogashira coupling of } \\
\text { aryl halides with } \\
\text { aromatic and aliphatic } \\
\text { terminal alkynes }\end{array}$ & [67] \\
\hline 24. & SBA-15/AO/Pd(0) & $\begin{array}{l}\text { Suzuki-Miyaura cross- } \\
\text { coupling of aryl halides } \\
\text { with phenylboronic acid }\end{array}$ & [68] \\
\hline
\end{tabular}


Table 3 continued

\begin{tabular}{|c|c|c|c|}
\hline S. no. & Nanocatalyst & Organic reaction & References \\
\hline 25. & $\begin{array}{l}\mathrm{Pd} / \mathrm{Fe}_{3} \mathrm{O}_{4} @ \text { chitosan- } \\
\text { Schiff base }\end{array}$ & $\begin{array}{l}\text { Suzuki-Miyaura and } \\
\text { Heck-Mizoroki C-C } \\
\text { coupling reactions }\end{array}$ & [69] \\
\hline 26. & Al-MSS-22 & $\begin{array}{l}\text { Esterification of ethanoic } \\
\text { acid with alcohols/ } \\
\text { polyols }\end{array}$ & [70] \\
\hline 27. & Sal-MSN & Epoxidation of styrene & [71] \\
\hline 28. & $\begin{array}{l}\text { Acid-base bi- } \\
\text { functionalized } \\
\text { mesoporous silica } \\
\text { nanoparticles }\end{array}$ & $\begin{array}{l}\text { One-pot conversion of } \\
\text { cellulose to } \\
\text { 5-hydroxymethylfurfural }\end{array}$ & [74] \\
\hline 29. & Co-MSN/MAO & $\begin{array}{l}\text { Polymerization of 1,3- } \\
\text { butadiene }\end{array}$ & [75] \\
\hline 30. & $\begin{array}{l}\mathrm{Zr(IV)-} \\
\text { HMNQ@ASMPs }\end{array}$ & $\begin{array}{l}\text { Friedel-Crafts, } \\
\text { Knoevenagel and } \\
\text { Pechmann condensation } \\
\text { reactions }\end{array}$ & [76] \\
\hline 31. & $\begin{array}{c}\mathrm{Cu}-2 \mathrm{QC} @ \mathrm{Am}- \\
\mathrm{SiO}_{2} @ \mathrm{Fe}_{3} \mathrm{O}_{4}\end{array}$ & $\begin{array}{l}\text { Synthesis of carbamates } \\
\text { via } \mathrm{C}-\mathrm{H} \text { activation of } \\
\text { formamides }\end{array}$ & [77] \\
\hline
\end{tabular}

materials possess remarkable properties, making them potentially useful in applications requiring surface reactivity of the solid substrates in the liquid phase. The importance of chelating agents is well known but their incorporation in nanotechnologies can increase their usability manifolds. The results discussed hereby are of referential importance to the design and synthesis of other multifunctional nanostructured materials (Table 3).

Open Access This article is distributed under the terms of the Creative Commons Attribution 4.0 International License (http://crea tivecommons.org/licenses/by/4.0/), which permits unrestricted use, distribution, and reproduction in any medium, provided you give appropriate credit to the original author(s) and the source, provide a link to the Creative Commons license, and indicate if changes were made.

\section{References}

1. Karimipour, G., Ghaedi, M., Sahraei, R., Daneshfar, A., Biyareh, M.N.: Modification of gold nanoparticle loaded on activated carbon with bis(4-methoxysalicylaldehyde)-1,2-phenylenediamine as new sorbent for enrichment of some metal ions. Biol. Trace Elem. Res. 145, 109-117 (2012)

2. Afkhami, A., Tehrani, SMd, Bagheri, H.: Simultaneous removal of heavy-metal ions in wastewater samples using nano-alumina modified with 2,4-dinitrophenylhydrazine. J. Hazard. Mater. 181, 836-844 (2010)

3. Li, R., He, Q., Hu, Z., Zhang, S., Zhang, L., Chang, X.: Highly selective solid-phase extraction of trace $\mathrm{Pd}(\mathrm{II})$ by murexide functionalized halloysite nanotubes. Anal. Chim. Acta 713, 136-144 (2012)

4. Sharma, R.K., Pant, P.: Solid phase extraction and determination of metal ions in aqueous samples using quercetin modified
Amberlite XAD-16 chelating polymer as metal extractant. Int. J. Environ. Anal. Chem. 87, 503-514 (2009)

5. Sharma, R.K., Pant, P.: Preconcentration and determination of trace metal ions from aqueous samples by newly developed gallic acid modified Amberlite XAD-16 chelating resin. J. Hazard. Mater. 163, 295-301 (2009)

6. Ghaedi, M., Mortazavi, K., Jamshidi, M., Roosta, M., Karami, B.: Oxidized multiwalled carbon nanotubes modified with 2-(2-hydroxy-5-nitrophenyl)-4,5-diphenyl imidazole for solid phase extraction and preconcentration of some metal ions. Toxicol. Environ. Chem. 94, 846-859 (2012)

7. Evangelou, M.W.H., Ebel, M., Schaeffer, A.: Chelate assisted phytoextraction of heavy metals from soil. Effect, mechanism, toxicity, and fate of chelating agents. Chemosphere. 68, 989-1003 (2007)

8. Turker, A.R.: New sorbents for solid-phase extraction for metal enrichment. CLEAN Soil Air Water. 35, 548-557 (2007)

9. Prabhakaran, D., Subramanian, M.S.: A new chelating sorbent for metal ion extraction under high saline conditions. Talanta. 59, 1227-1236 (2003)

10. Mikhailov, O.V.: Molecular nanotechnologies of gelatin-immobilization using macrocyclic metal chelates. Nano Rev. 5, 21485 (2014)

11. Sahiner, N.: Soft and flexible hydrogel templates of different sizes and various functionalities for metal nanoparticle preparation and their use in catalysis. Prog. Polym. Sci. 38, 1329-1356 (2013)

12. Chen, B., Li, F., Huang, Z., Lu, T., Yuan, Y., Yuc, J., Yuan, G.: Self-assembled nanostructures of $\mathrm{Ag}_{6}\left[\mathrm{PV}_{3} \mathrm{Mo}_{9} \mathrm{O}_{40}\right]$ with $\mathrm{N}$-donor ligands and their catalytic activity. RSC Adv. 2, 11449-11456 (2012)

13. Wang, L., Yang, R.T.: New nanostructured sorbents for desulfurization of natural gas. Front. Chem. Sci. Eng. 8, 8-19 (2014)

14. Sharma, R.K., Sharma, S., Gulati, S., Pandey, A.: Fabrication of a novel nano-composite carbon paste sensor based on silica-nanospheres functionalized with isatin thiosemicarbazone for potentiometric monitoring of $\mathrm{Cu}^{2+}$ ions in real samples. Anal. Methods 5, 1414-1426 (2013)

15. Ezoddina, M., Shemirania, F., Abdib, K., Saghezchia, M.K., Jamali, M.R.: Application of modified nano-alumina as a solid phase extraction sorbent for the preconcentration of $\mathrm{Cd}$ and $\mathrm{Pb}$ in water and herbal samples prior to flame atomic absorption spectrometry determination. J. Hazard. Mater. 178, 900-905 (2010)

16. Sharma, R.K., Gulati, S., Pandey, A., Adholeya, A.: Novel, efficient and recyclable silica based organic-inorganic hybrid nickel catalyst for degradation of dye pollutants in a newly designed chemical reactor. Appl. Catal. B 125, 247-258 (2012)

17. Sharma, R.K., Gulati, S.: Manganese phthalocyanine immobilized on silica gel: efficient and recyclable catalyst for single-step oxidative esterification of aldehydes with alcohols. J. Mol. Catal. A Chem. 363, 291-303 (2012)

18. Sharma, R.K., Gulati, S., Pandey, A.: Polyfluorinatedzinc(II)phthalocyanine complex immobilized on silica: a novel, highly selective and recyclable inorganic-organic hybrid catalyst for the synthesis of biologically important 1,5-benzodiazepines. Inorg. Chim. Acta 397, 21-31 (2013)

19. Gawandea, M.B., Mongab, Y., Zborila, R., Sharma, R.K.: Silicadecorated magnetic nanocomposites for catalytic applications. Coord. Chem. Rev. 288, 118-143 (2015)

20. Azgomi, N., Mokhtary, M.: Nano- $\mathrm{Fe}_{3} \mathrm{O}_{4} @ \mathrm{SiO}_{2}$ supported ionic liquid as an efficient catalyst for the synthesis of 1,3-thiazolidin4-ones under solvent-free conditions. J. Mol. Catal. A Chem. 398, 58-64 (2015)

21. Dai, S., Burleigh, M.C., Ju, Y.H., Gao, H.J., Lin, J.S., Pennycook, J.S., Barnes, C.E., Xue, Z.L.: Hierarchically imprinted sorbents 
for the separation of metal ions. J. Am. Chem. Soc. 122, 992-993 (2000)

22. Lagadic, I.L., Mitchell, M.K., Payne, B.D.: Highly effective adsorption of heavy metal ions by a thiol-functionalized magnesium phyllosilicate clay. Environ. Sci. Technol. 35, 984-990 (2001)

23. Sierra, I., Quintanilla, D.P.: Heavy metal complexation on hybrid mesoporous silicas: an approach to analytical applications. Chem. Soc. Rev. 42, 3792-3807 (2013)

24. Cruz, P., Perez, Y., Hierro, I., Fernández-Galán, R., Fajardo, M.: $\varepsilon$-Caprolactone polymerization using titanium complexes immobilized onto silica based materials functionalized with ionic liquids: insights into steric, electronic and support effects. RSC Adv. 6, 19723-19733 (2016)

25. Quintanilla, D.P., Sanchez, A., Hierro, I., Fajardo, M., Sierra, I.: Functionalized HMS mesoporous silica as solid phase extractant for $\mathrm{Pb}$ (II) prior to its determination by flame atomic absorption spectrometry. J. Sep. Sci. 30, 1556-1567 (2007)

26. Jiang, Z., Xie, J., Jiang, D., Jing, J., Qin, H.: Facile route fabrication of nano-Ni core mesoporous-silica shell particles with high catalytic activity towards 4-nitrophenol reduction. CrystEngComm. 14, 4601-4611 (2012)

27. Yang, H., Wang, S.F., Xian, T., Wei, Z.Q., Feng, W.J.: Fabrication and photocatalytic activity of $\mathrm{YMn}_{2} \mathrm{O}_{5}$ nanoparticles. Mater. Lett. 65, 884-886 (2011)

28. Wang, D., Xu, L., Wu, P.: Hierarchical, core-shell meso-ZSM$5 @$ mesoporous aluminosilicate-supported Pt nanoparticles for bifunctional hydrocracking. J. Mater. Chem. A 2, 15535 (2012). doi: $10.1039 / \mathrm{c} 4 \mathrm{ta} 02740 \mathrm{j}$

29. Uygun, D.A., Senay, R.H., Turkcan, C., Akgol, S., Denizli, A.: Metal-chelating nanopolymers for antibody purification from human plasma. Appl. Biochem. Biotechnol. 168, 1528-1539 (2012)

30. Bonda, D.J., Liu, G., Men, P., Perry, G., Smith, M.A., Zhu, X.: Nanoparticle delivery of transition-metal chelators to the brain: oxidative stress will never see it coming! CNS Neurol. Disord. Drug Targets 11, 81-85 (2012)

31. Dehdashtian, S., Gholivand, MdB, Shamsipur, M., Karimi, Z.: A nano sized functionalized mesoporous silica modified carbon paste electrode as a novel, simple, robust and selective anti-diabetic metformin sensor. Sens. Actuators B Chem. 221, 807-815 (2015)

32. Liu, G., Garretta, M.R., Men, P., Zhua, X., Perrya, G., Smith, M.A.: Nanoparticle and other metal chelation therapeutics in Alzheimer disease. Biochim. Biophys. Acta 1741, 246-252 (2005)

33. Zhao, X.N., Shi, Q.Z., Xie, G.H., Zhou, Q.X.: $\mathrm{TiO}_{2}$ nanotubes: a novel solid phase extraction adsorbent for the sensitive determination of nickel in environmental water samples. Chin. Chem. Lett. 19, 865-867 (2008)

34. Lestan, D., Luo, C., Li, X.: The use of chelating agents in the remediation of metal-contaminated soils. Environ. Pollut. 153, 3-13 (2008)

35. Yazdi, A.V., Beckman, E.J.: Design, synthesis, and evaluation of novel, highly $\mathrm{CO}_{2}$-soluble chelating agents for removal of metals. Ind. Eng. Chem. Res. 35, 3644-3652 (1996)

36. Baezzat, M.R., Maleki, H., Moghadamhosseyni, E., Tabandeh, M.: Determination of trace amounts of zinc, iron and copper by flame atomic absorption after their preconcentration using sodium dodecyl sulfate (SDS) coated alumina nanoparticles modified with 3-mercapto-D-valin from environmental samples. Am. J. Anal. Chem. 5, 1228-1238 (2014)

37. Zhai, Y., He, Q., Han, Q., Duan, S.: Solid-phase extraction of trace metal ions with magnetic nanoparticles modified with 2,6diaminopyridine. Microchim. Acta 178, 405-412 (2012)
38. Huang, C., Hu, B.: Silica-coated magnetic nanoparticles modified with $\gamma$-mercaptopropyltrimethoxysilane for fast and selective solid phase extraction of trace amounts of $\mathrm{Cd}, \mathrm{Cu}, \mathrm{Hg}$, and $\mathrm{Pb}$ in environmental and biological samples prior to their determination by inductively coupled plasma mass spectrometry. Spectrochim. Acta Part B 63, 437-444 (2008)

39. Ozmen, M., Can, K., Arslan, G., Tor, A., Cengeloglu, Y., Ersoz, M.: Adsorption of $\mathrm{Cu}(\mathrm{II})$ from aqueous solution by using modified $\mathrm{Fe}_{3} \mathrm{O}_{4}$ magnetic nanoparticles. Desalination. 254, 162-169 (2010)

40. Cheng, G., He, M., Peng, H., Hu, B.: Dithizone modified magnetic nanoparticles for fast and selective solid phase extraction of trace elements in environmental and biological samples prior to their determination by ICP-OES. Talanta. 88, 507-515 (2012)

41. Suleiman, J.S., Hu, B., Peng, H., Huang, C.: Separation/preconcentration of trace amounts of $\mathrm{Cr}, \mathrm{Cu}$ and $\mathrm{Pb}$ in environmental samples by magnetic solid-phase extraction with bismuthiol-IIimmobilized magnetic nanoparticles and their determination by ICP-OES. Talanta. 77, 1579-1583 (2009)

42. Awual, MdR, Hasan, MdM, Znad, H.: Organic-inorganic based nano-conjugate adsorbent for selective palladium(II) detection, separation and recovery. Chem. Eng. J. 259, 611-619 (2015)

43. Sharma, R.K., Gulati, S., Sachdeva, S.: One pot and solvent-free synthesis of 2,9,16,23-tetrachlorometal(II) phthalocyanines. Green Chem. Lett. Rev. 5, 83-87 (2012)

44. Sharma, R.K., Gulati, S., Mehta, S.: Preparation of gold nanoparticles using tea: a green chemistry experiment. J. Chem. Educ. 89, 1316-1318 (2012)

45. Soylakab, M., Yilmaza, E., Ghaedic, M., Montazerozohori, M.: Solid phase extraction on multiwalled carbon nanotubes and flame atomic absorption spectrometry combination for determination of some metal ions in environmental and food samples. Toxicol. Environ. Chem. 93, 873-885 (2011)

46. Zhanga, M., Yanga, H., Xiana, T., Wei, Z.Q., Jiang, J.L., Feng, Y.C., Liu, X.Q.: Polyacrylamide gel synthesis and photocatalytic performance of $\mathrm{Bi}_{2} \mathrm{Fe}_{4} \mathrm{O}_{9}$ nanoparticles. J. Alloys Compd. 509, 809-812 (2011)

47. Du, X., He, J.: Amino-functionalized silica nanoparticles with center-radially hierarchical mesopores as ideal catalyst carriers. Nanoscale. 4, 852-859 (2012)

48. Sharma, R.K., Monga, Y., Puri, A.: Magnetically separable silica@ $\mathrm{Fe}_{3} \mathrm{O}_{4}$ core-shell supported nano-structured copper(II) composites as a versatile catalyst for the reduction of nitroarenes in aqueous medium at room temperature. J. Mol. Catal. A Chem. 393, 84-95 (2014)

49. Negroa, E., Videlab, A.H.A.M., Baglioc, V., Aricòc, A.S., Specchiab, S., Kopera, G.J.M.: Fe-N supported on graphitic carbon nano-networks grown from cobalt as oxygen reduction catalysts for low-temperature fuel cells. Appl. Catal. B 166-167, 75-83 (2015)

50. Veerakumara, P., Velayudhamb, M., Lub, K., Rajagopal, S.: Polyelectrolyte encapsulated gold nanoparticles as efficient active catalyst for reduction of nitro compounds by kinetic method. Appl. Catal. A Gen. 439-440, 197-205 (2012)

51. Oh, H., Oh, J., Roh, B., Hwang, I., Kim, H.: Development of highly active and stable non-precious oxygen reduction catalysts for PEM fuel cells using polypyrrole and a chelating agent. Electrochem. Commun. 13, 879-881 (2011)

52. Makarova, O.V., Rajh, T., Thurnauer, M.C.: Surface modification of $\mathrm{TiO}_{2}$ nanoparticles for photochemical reduction of nitrobenzene. Environ. Sci. Technol. 34, 4797-4803 (2000)

53. Wang, P., Fan, C., Wang, Y., Ding, G., Yuan, P.: A dual chelating sol-gel synthesis of $\mathrm{BaTiO}_{3}$ nanoparticles with effective photocatalytic activity for removing humic acid from water. Mater. Res. Bull. 48, 869-877 (2013) 
54. Habibi, MdH, Mokhtari, R.: Novel sulfur-doped niobium pentoxide nanoparticles: fabrication, characterization, visible light sensitization and redox charge transfer study. J. Sol Gel Sci. Technol. 59, 352-357 (2011)

55. Sun, W., Xie, M., Jing, L., Luan, Y., Fu, H.: Synthesis of large surface area nano-sized $\mathrm{BiVO}_{4}$ by an EDTA-modified hydrothermal process and its enhanced visible photocatalytic activity. J. Solid State Chem. 184, 3050-3054 (2011)

56. Saien, J., Mesgari, Z.: Highly efficient visible-light photocatalyst of nitrogen-doped $\mathrm{TiO}_{2}$ nanoparticles sensitized by hematoporphyrin. J. Mol. Catal. A Chem. 414, 108-115 (2016)

57. Tianbin, W., Peng, Z., Jun, M., Honglei, F., Weitao, W., Tao, J., Buxing, H.: Catalytic activity of immobilized Ru nanoparticles in a porous metal-organic framework using supercritical fluid. Chin. J. Catal. 34, 167-175 (2013)

58. Qureshi, Z.S., Sarawade, P.B., Albert, M., D’Elia, V., Hedhili, MdN, Kohler, K., Basset, J.: Palladium nanoparticles supported on fibrous-structured silica nanospheres (KCC-1): an efficient and selective catalyst for the transfer hydrogenation of alkenes. ChemCatChem. 7, 635-642 (2015)

59. Sharma, R.K., Sharma, S.: Silica nanospheres supported palladium(II) furfural complex as highly efficient and recyclable catalyst for oxidative amination of aldehydes. Dalton Trans. 43, 1292-1304 (2014)

60. Gholivand, MdB, Azadbakht, A.: A nano-structured Ni(II)-chelidamic acid modified gold nanoparticle self-assembled electrode for electrocatalytic oxidation and determination of methanol. Mater. Sci. Eng. C 32, 1955-1962 (2012)

61. Kumar, R.T., Suresh, P., Selvam, N.C.S., Kennedy, L.J., Vijaya, J.J.: Comparative study of nano copper aluminate spinel prepared by sol-gel and modified sol-gel techniques: structural, electrical, optical and catalytic studies. J. Alloys Compd. 522, 39-45 (2012)

62. Cruz, P., Perez, Y., Hierro, I., Fajardo, M.: Copper, copper oxide nanoparticles and copper complexes supported on mesoporous SBA15 as catalysts in the selective oxidation of benzyl alcohol in aqueous phase. Microporous Mesoporous Mater. 220, 136-147 (2016)

63. Pandey, S., Saha, A., Jana, S., Pal, T.: Resin-immobilized CuO and $\mathrm{Cu}$ nanocomposites for alcohol oxidation. Org. Lett. 10, 5179-5181 (2008)

64. Dutta, P., Sarkar, A.: Palladium nanoparticles immobilized on chemically modified silica gel: efficient heterogeneous catalyst for Suzuki, Stille and Sonogashira cross-coupling reactions. Adv. Synth. Catal. 353, 2814-2822 (2011)

65. He, W., Zhang, F., Li, H.: Active and reusable Pd(II) organometallic catalyst covalently bonded to mesoporous silica nanospheres for water-medium organic reactions. Chem. Sci. 2, 961-966 (2011)

66. Mondal, P., Banerjee, S., Roy, A.S., Mandal, T.K., Islam, S.M.: In situ prepared mesoporous silica nanosphere supported palladium(II) 2-aminopyridine complex catalyst for Suzuki-Miyaura cross-coupling reaction in water. J. Mater. Chem. 22, 20434-20442 (2012)
67. Isfahani, A.L., Baltork, I.M., Mirkhani, V., Khosropour, A.R., Moghadam, M., Tangestaninejad, S.: Pd nanoparticles immobilized on nanosilica triazine dendritic polymer: a reusable catalyst for the synthesis of mono-, di-, and trialkynylaromatics by Sonogashira cross-coupling in water. Eur. J. Org. Chem. 5603-5609 (2014). doi:10.1002/ejoc.201402503

68. Vaghei, R.G., Hemmati, S., Veisi, H.: Pd immobilized on amidoxime-functionalized mesoporous SBA-15: a novel and highly active heterogeneous catalyst for Suzuki-Miyaura coupling reactions. J. Mol. Catal. A Gen. 393, 240-247 (2014)

69. Naghipour, A., Fakhri, A.: Heterogeneous $\mathrm{Fe}_{3} \mathrm{O}_{4} @$ chitosanSchiff base Pd nanocatalyst: fabrication, characterization and application as highly efficient and magnetically-recoverable catalyst for Suzuki-Miyaura and Heck-Mizoroki C-C coupling reactions. Catal. Commun. 73, 39-45 (2016)

70. Nyalosaso, J.L., Derrien, G., Charney, C., de Menorval, L.C., Zajac, J.: Aluminium-derivatized silica monodisperse nanospheres by a one-step synthesis-functionalization method and application as acid catalysts in liquid phase. J. Mater. Chem. 22, 1459-1468 (2012)

71. Tang, D., Zhang, W., Zhang, Y., Qiao, Z., Liu, Y., Huo, Q.: Transition metal complexes on mesoporous silica nanoparticles as highly efficient catalysts for epoxidation of styrene. J. Colloid Interface Sci. 356, 262-266 (2011)

72. Li, Z., Peng, Q., Yuan, Y.: Aqueous phosphine-Rh complexes supported on non-porous fumed-silica nanoparticles for higher olefin hydroformylation. Appl. Catal. A 239, 79-86 (2003)

73. Chen, H., Huh, S., Wiench, J.W., Pruski, M., Lin, V.S.Y.: Dialkylaminopyridine-functionalized mesoporous silica nanosphere as an efficient and highly stable heterogeneous nucleophilic catalyst. J. Am. Chem. Soc. 127, 13305-13311 (2005)

74. Peng, Y., Lee, Y., Wu, C., Wu, K.C.W.: Acid-base bi-functionalized, large-pored mesoporous silica nanoparticles for cooperative catalysis of one-pot cellulose-to-HMF conversion. J. Mater. Chem. 22, 23181-23185 (2012)

75. Tang, D., Zhang, L., Zhang, Y., Qiao, Z., Liu, Y., Huo, Q.: Mesoporous silica nanoparticles immobilized salicylaldimine cobalt complexes as high efficient catalysts for polymerization of 1,3-butadiene. J. Colloid Interface Sci. 369, 338-343 (2012)

76. Sharma, R.K., Monga, Y., Puri, A.: Zirconium(IV)-modified silica@magnetic nanocomposites: fabrication, characterization and application as efficient, selective and reusable nanocatalysts for Friedel-Crafts, Knoevenagel and Pechmann condensation reactions. Catal. Commun. 35, 110-114 (2013)

77. Sharma, R.K., Dutta, S., Sharma, S.: Quinoline-2-carboimine copper complex immobilized on amine functionalized silica coated magnetite nanoparticles: a novel and magnetically retrievable catalyst for the synthesis of carbamates via $\mathrm{C}-\mathrm{H}$ activation of formamides. Dalton Trans. 44, 1303-1316 (2015) 